\title{
Artes decorativas en la Granada moderna según los escribanos de la ciudad
}

\author{
GILA MEDINA, Lázaro \\ Universidad de Granada, Granada, 2017
}

Son numerosos los especialistas que han teorizado sobre la importancia y utilidad de las fuentes literarias y documentales para la investigación en historia del arte, destacándose, entre la variada y diversa tipología de las segundas, el enorme interés de la información procedente de los protocolos notariales (contratos de obras, testamentos e inventarios post mortem, cartas de pago, escrituras de aprendizaje...) para, entre otros asuntos, replantear muchas cuestiones relativas a temas de la historia social del arte, pero también, como señala acertadamente Muñoz Jiménez, «para conocer en profundidad la realidad histórica-artística de una localidad, escuela o centro creador» (1996 : 393). De acuerdo con esto, a nadie se le escapa el relevante papel de Granada en el contexto del arte español de la Edad Moderna -y más aún en el de Andalucía Oriental-, tanto en el ámbito de la arquitectura y las artes figurativas, como en el de otras actividades relacionadas con el arte y la artesanía, reunidas bajo el epígrafe "decorativas". La tarea de fundamentación documental de la investigación por parte de los estudiosos de cada una de estas especialidades se ha apoyado tradicionalmente en la información extraída de los fondos de distintos archivos granadinos, lo mismo civiles que eclesiásticos, pero faltaba la procedente de la colección de protocolos notariales, poco consultada debido a la falsa creencia, extendida entre los investigadores, de que sus fondos habían desaparecido casi en su totalidad tras el voraz incendio que en 1879 sufrió la Casa de los Miradores de plaza de Bib-Rambla, donde estaban depositados desde 1862. Sus consecuencias, siendo muy graves, no supusieron sin embargo la destrucción total del archivo, pues solo del período comprendido entre los siglos XVI y XVIII se conservan 1.351 legajos.

La comentada escasez de información notarial ha sido paliada en parte -por las circunstancias referidas- gracias al metódico plan de investigación documental sobre las artes y los artífices granadinos de las centurias modernas llevado a cabo por el profesor Lázaro Gila Medina en el Archivo Histórico del llustre Colegio Notarial de Granada a lo largo de

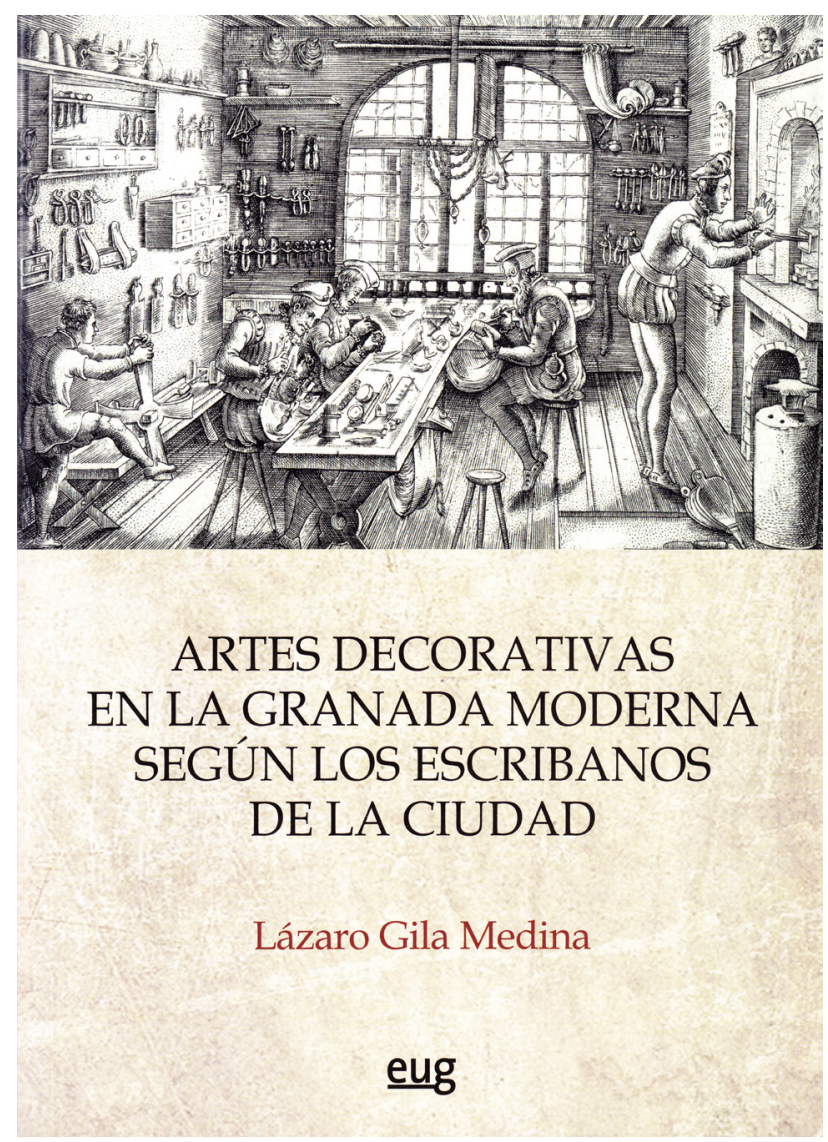

los últimos quince años, tiempo en el que ha simultaneado la labor de transcripción paleográfica (ardua e ingrata donde las haya), con la actividad docente y la dedicación a la historia del arte como reconocido especialista en escultura barroca granadina, además de en otros variados asuntos de la disciplina.

Artes Decorativas en la Granada Moderna... es resultado precisamente de este trabajo de recopilación de datos e información inéditos en el archivo histórico, y supone la continuación de otros dos libros anteriores publicados en 2000 y 2008 dedicados, respectivamente, a los maestros de cantería y albañilería, y a los de carpintería; de este fondo 
procede así mismo parte de la documentación de la monografía Pedro de Mena. Documentos y textos (Málaga, 2013), de la que Lázaro Gila es coautor con José Martínez Galisteo, y de numerosos artículos publicados en los últimos años. En el libro que reseñamos figuran regestados 1.461 documentos -fechados entre los años 1508 y 1790- referidos a la actividad profesional y la vida privada de numerosos maestros, oficiales y aprendices, muchos de ellos desconocidos, dedicados al trabajo del bordado, con un total de 97 artífices identificados; de fundir campanas, con 12; del hierro, de hacer rejas y de la cerrajería, con 253 y, por último, del de la plata, del que se anotan 613 individuos, cifra que, comparada con las anteriores, demuestra la importancia del Arte y Cofradía de San Eloy -cuya existencia en la capital se data por primera vez en el testamento del maestro Gonzalo de Herrera, fechado en 1545, aunque parece evidente que su origen sea anterior- y del colectivo de plateros en el día a día de una ciudad como Granada, convertida entonces en «centro artístico de importancia capital», en palabras del profesor Gila Medina.

Entre tantos nombres, hay un buen número que cuenta ya en su biografía con obras documentadas, algunas conservadas todavía, y noticias procedentes de otros archivos a las que vienen a sumarse las proporcionadas por este libro que, en el caso de ciertos artífices, son numerosas. Es lo que ocurre, por ejemplo, con la información conocida ahora de destacados maestros bordadores, como Pedro de Flandes (con documentos desde 1546 a 1566), Juan de Olarte (1558-1575), Baltasar Pizarro (1568-1605) y Alonso de Villarroel (1597-1606), que desplegaron una notable actividad para la catedral e iglesias de la capital y provincia. También con los datos sacados a la luz del maestro campanero Benito del Campo y Vega (1689-1715), fundidor, entre otras, de las campanas San Pedro (conocida también como «la Petra») y Santa Bárbara o «Pascuala» de la catedral. Relevantes son así mismo los testimonios aportados de los plateros Juan de Castro (1555-1564); Melchor de la Hoz (1563-†1567), artista notabilísimo y autor de la magnífica cruz procesional de la Colegiata de Santa Fe (c. 1565), comparable por su calidad con las mejores de la platería hispánica del momento, y de otra cruz, así mismo conservada, para la parroquia de Montejícar; Francisco Téllez (1563-1574), platero de fábrica de la catedral y a quien se debe la reforma de la custodia del Corpus donada por la reina Isabel en 1501, y Diego de
Cervantes (1640-1677), también platero de fábrica y responsable de la hechura de las dos lámparas de la capilla mayor (1654), que trazó Alonso Cano, y del arca eucarística del Jueves Santo, así como de un juego de candeleros para la catedral de Guadix, por citar las más conocidas.

Respecto al método seguido para clasificar y ordenar los documentos, es preciso señalar que el autor utiliza el normalizado para la documentación histórica, esto es, el de disponerlos numerados correlativamente por orden cronológico, contando cada uno de ellos con un extracto del documento y de las necesarias referencias archivísticas para identificarlos. Además, para facilitar la consulta de los mismos, el libro se acompaña al final de un índice onomástico y de otro toponímico, a la vez que de una muy útil relación alfabética de maestros por especialidades con los años en que están documentados en el protocolo notarial.

En suma, una necesaria y muy útil aportación al conocimiento documental de estos sectores del arte -nunca «menores»- y de sus artífices en Granada, puesta generosamente por el profesor Gila Medina a disposición de los investigadores y especialistas. Con este libro y los anteriores, citados más arriba, su autor prosigue la senda de otros reputados expertos en documentación histórica, en una tarea que cuenta con una larga tradición en la historiografía del arte español de la Edad Moderna, destacando, entre otras muchas contribuciones y por citar solo un ejemplo cercano, la fundamental del agustino Andrés Llordén (†1986) sobre la historia del arte en Málaga, seguramente uno de los precedentes más destacados en esta línea de investigación centrada en el estudio y transcripción de centenares de documentos de los riquísimos fondos notariales.

Rafael Sánchez-Lafuente Gémar Universidad de Málaga

\section{Bibliografía}

MUÑOZ JIMÉNEZ, José Miguel (1996), «El protocolo notarial como fuente para la Historia del Arte», en La investigación y las fuentes documentales de los archivos. (I y || Jornadas sobre Investigación en Archivos), ANABAD, Castilla-La Mancha Asociación de amigos del Archivo Histórico Provincial, Guadalajara, vol. I, p. 393. 